The review a controlled collaborative, system wide partnership, with open and democratic stakeholder engagement and review lasting over 12 months. A panel of key engaged committed members, including: patients, carers, MPs, health and social care services, charities, faith groups, commissioners, GPs, specialist practitioners and the wider workforce including volunteers.

Critical success factors:

- Keeping patients and carers as our focus

- Partner relationship building with early participation

- The creation of excitement and new thinking by being brave and challenging the status quo

- High quality project management and external support

- Sustainability.

Wide ranging evidence and data has come from: external speakers, clinicians, patients, carers and families, and the general public through structured stakeholder engagement events, focus groups and surveys and analysis through desk top research by external consultants.

Outcomes Key themes are emerging and being developed which will lead to a new sustainable model of care with a countywide, cross agency partnership approach, sharing resources and innovations, with patient care as the driver

- A blended solution, with the hospice as a central enabler, to facilitate a caring network that will provide secure

"touchpoints" of professional care and support when and where it has the most impact

- New community-based solutions: supporting early and timely referral, care closer to home using

- Collaboration and interoperability with the wider community: macro partnerships with micro- enterprise solutions

- Innovation and digital connectivity

- The workforce including volunteers

- Fundraising including income growth, branding and marketing

Reinforced Learning: Collaborate... or deteriorate!

\section{P-184 PARTNERSHIP WORKING WITH LOCAL AMBULANCE SERVICES}

Linda Coffey, Dawn Dark. ellenor, Gravesend, UK

10.1136/bmjspcare-2016-001245.206

Background Patients in the community setting wishing to be cared for and die at home often end up in the A\&E department. Primary responders to patients are usually the ambulance services. The reasons for this are varied but access to specialist palliative care support has been shown to be effective at reducing $\mathrm{A} \& \mathrm{E}$ attendance. The project aimed to improve the knowledge of staff, within the Local Ambulance Service (LAS), focusing on identifying when a patient is dying and what alternative support is available.

Aims

- Increase knowledge to identify dying patient and support available

- Reduce hospital attendance particularly at End of Life (EoL)

- Achieve Preferred Place of Care for patients

- Develop further partnership working.
Approach Hospice staff in conjunction with LAS leads set up three evening training sessions for LAS staff. Sessions covered the services provided by the hospice, symptom control, palliative care emergencies, identification of dying and encouraged crews to "pick up the phone" for advice. Each session was planned for two hours allowing ample opportunity for discussion.

Outcomes Anonymous feedback was obtained from the 55 attendees:

- $100 \%$ reported they now feel more confident in dealing with patients at EoL

- $100 \%$ identified they feel more confident to call the 24 hour hospice on call service as and when they need advice.

Frequent comments:

- Being able to identify when a patient is dying was most helpful

- Realised that advice available is not restricted to patients known to the hospice.

Conclusion Knowledge has improved with crews recognising patients at end-of-life and contacting the hospice on call service appropriately. Patient choice has been supported ensuring that their Preferred Place of Care at end-of-life is met. Partnership working has improved with further training sessions planned across the county.

\section{P-185 COLLABORATIVE CONTRACTING: ENSURING HARMONY NOT CONTRADICTION}

Helen Franklin. Phyllis Tuckwell Memorial Hospice Limited, Farnham, UK

\subsection{6/bmjspcare-2016-001245.207}

A new era is dawning in the commissioning and provision of primary health care. The visionaries promote greater integration of care, encourage creative contracting, and above all inspire collaboration across providers to achieve best patient care. This will give rise to a new style of provider partnerships. Where does this leave end of life care in the voluntary sector? It is vital that the passion and independence of what we do is sustained throughout the maelstrom of oncoming change but equally important that we contribute, collaborate and continue to lead and provide best practice end of life care no matter how the contractual landscape might change.

This paper will address some key contractual issues for consideration by the voluntary sector when seeking to be involved in the new-style provider partnerships. It will cover legal aspects of confidentiality agreements, exclusivity arrangements, sub-contracts and the operation of TUPE. Whilst the collaborative approach is characterised by shared accountability and a high level of inter-organisational trust, as in other sectors this can often translate into robust traditional-style contractual regimes at odds with those core values on which the partnership is founded.

This paper considers these aspects from the voluntary provider perspective. It reflects our experience as transferee in a TUPE transfer of end of life services from a private provider to us as independent hospice and explains how that has informed our thinking going forward. To conclude we shall propose guiding principles to underpin a form of collaboration agreement pursuant to which the Hospice provider may work alongside the new-style provider partnerships to ensure appropriate delivery of valuable support of the partnerships' desired end of life outcomes. 